\title{
HUME ON TESTIMONY TO THE MIRACULOUS
}

\author{
BRUCE LANGTRY*
}

Hume's Enquiry, Section X, Part I, may be seen as consisting, firstly, of a discussion of principles for evaluating testimony to the extraordinary and marvellous; and secondly, of an application of the results of that discussion to the evaluation of testimony to the miraculous.

The conclusion of the first stage of the discussion is as follows:

"Suppose, for instance, that the fact, which the testimony endeavours to establish, partakes of the extraordinary and the marvellous; in that case, the evidence, resulting from the testimony, admits of a diminution, greater or lcss, in proportion as the fact is more or less unusual ... When the fact attested is such a one as has seldom fallen under our observation, here is a contest of two experiments; of which the one destroys the other, as far as its force goes, and the inferior can only operate on the mind by the force which remains. The very same principle of experience, which gives us a certain degree of assurance in the testimony of witnesses, gives us also, in this case, another degree of assurance against the fact which they endeavour to establish; from which contradiction there necessarily arises a counterpoise, and mutual destruction of belief and authority."1

The tasks of interpretation and assessment are very much bound up together. One rendering of the first sentence would be as follows: the degree to which a piece of testimony supports the hypothesis that an E-type event occurred is directly proportional to the frequency with which E-type events have occurred in the past. However, the second sentence quoted, and indecd the whole way Hume has developed the argument earlicr in the section, suggests that the important thing is the frequency with which E-type cvents have been observed to have occurred in the past. Moreover, the present rendering makes it hard to understand Hume's supposition three paragraphs later that "the testimony considered apart and in itself amounts to an entire proof".

An improved version would be: the measure of confidence which one should have in the hypothesis that an E-type event occurred is

University of Sydney.

1 D. Hume, Enquiry Concerning Human Understanding, ed. S. A. SelbyBigge (second edition, Oxford 1902), page 113. 
proportional not only to the degree to which that hypothesis is supported by the available testimony considered in itself, but also to the frequency with which E-type events have been observed in the past.

Yet this would hardly be a charitable interpretation of Hume, for as it stands the statement is false. Suppose that following each draw from a pack of cards, the card drawn is returned to the pack and the pack reshuffled; then after a long sequence of draws we will have observed the ace of spades to have been drawn with a frequency of $1 / 52$. Before each draw is made we do have a certain degree of assurance against the hypothesis that the next card drawn will be the ace of snades - the probability is only $1 / 52$. But this is no reason against believing a witness's testimony that on some particular occasion the card drawn was the ace of spades.

It will be pointed out that before the drawing every other outcome was equally improbablc. Thi; may suggest yet another formulation of Hume's conclusion. The measure of confidence which one should have in the hypothesis that an E-typs event occurred in a situation of type $S$ is proportional not only to the degree to which that hypothesis is supported by the available testimony considered in itself, but also to the proportion by which the frequency with which E-type events have been obscrved in situations of type $S$ is greater or less than the frequencies with which each of the various other possible outcomes have been observed in situations of type S.

But this is still unsatisfactory. Suppose we are told the pack contains one acc of spades and 51 queens of hearts. Then we may still be justifind in believing a normally reliable witness's testimony that on som? particular occasion the ace of spades was drawn. ${ }^{2}$ If Hume's language suggests that thera is some simple multiplying or subtracting of probabilities, th $\_n$ thi : wnuld be mistaken. It remains unclear how we are to render Hume's thesis in plausible form.

There are further over-arching difficultics for the way Hume puts things. He speaks as if the only evidence we have for the truth of some generalisation is obscrvation of instances which fall under it. This, of course, is mistaken. We now realise that an Indian prince could have theoretical evidenc ${ }^{n}$ that water would solidify at temperatures below $273^{\circ} \mathrm{A}$, even though he himself had never observed this phenomenon, or heard reliable reports of it. In this sense it is false that "all probability supposes an opposition of experiments and

\footnotetext{
2 Furthermore, suppose that two witnerses disagree over whether on a particular occasion an ace of spad ss or a queen of hearts was drawn. Our decision is not virtually settled by the much higher antecedent probability of drawing a queen of hearts; it will be made on the basis of who had the better view, who is in general a more reliable observer, etc.
} 


\section{SOPHIA}

observations"; although it is true no doubt that our evidence for a ziven hypothesis rests on observation at some point - but this is to say little.

Let us not continue to press this point, but rather restate something like Hume's position in terms of an example. Suppose that one group of witnesses report that all of one hundred $F$ objects they have observed have been $G$, while another group of witnesses report that they have observed some other $F$ which was not $G$. The question is whether we are to believe that there cxists an $F$ which is not $G$. We can set out the situation as follows:

$w_{1}$ : The first group of witnesses report, " $F a_{1}, G_{1}, F_{2}, G a_{2}, F a_{1}$. $\mathrm{Ga}_{3}, \ldots \mathrm{Fa}_{100} . \mathrm{Ga}_{100}$, and these were all the $\mathrm{F}$ objects that we saw".

$\mathrm{w}_{2}$ : The second group of witnesses report, "Fa, $\sim \mathrm{Ga}_{n}$ " (n 100).

$h_{1}: F_{1}, G a_{1}, F_{2}, G a_{2}, F a_{3}, G a_{3}, \ldots a_{100} . G a_{100}$.

$\left.\mathrm{h}_{2}: \mathrm{Fa}_{n}\right) \mathrm{Ga}_{n}$.

$h_{3}: F a_{n} \cdot \sim G a_{n}$, ie., negation of $h_{2}$.

Read " $S(x, y)>S(z, w)$ " as " $x$ supports $y$ more than $z$ supports w".

The Humean view is that "all probability supposes an opposition of experiments and observations, wherc the one side is found to overbalance the other, and to produce a degree of evidence proportioned to the supcriority". Therefore the just conclusion will depend on our weighing one group of reports against the other. That is, the choice between $h_{2}$ and $h_{2}$ must be on the basis of which hypothesis is better supported by (more probable on) the evidence. The question of which hypothesis is better supported by the evidence is the question of which set of reports is more reliablc. Therefore we are obliged to accept $h_{2}$ rather than $h_{3}$ if and only if it is more likely that the second group of witnesses was mistaken in its report than that the first group of witnesses is mistaken.

This argument is unsound. What is meant by saying that the first group of witnesses is more reliable, i.e. less likely to be mistaken about the truth of what they reported, is that $S\left(w_{1}, h_{1}\right)>S\left(w_{2} h_{3}\right)$. Now the Humean sees each of the two contradictory hypotheses $h_{2}$ and $h_{3}$ as being supported by one or the other of the conflicting, though not contrary, statements $w_{1}$ and $w_{2}$, and asks which hypothesis is better supported by that evidence-statement in its favour. This is the question of whether $S\left(w_{1}, h_{2}\right)>S\left(w_{2}, h_{3}\right)$. But "S $\left(\mathrm{w}_{1}, \mathrm{~h}_{2}\right)>\mathrm{S}\left(\mathrm{w}_{2}, \mathrm{~h}_{3}\right)$ " does not follow from " $\mathrm{S}\left(\mathrm{w}_{1}, \mathrm{~h}_{1}\right)>$ $S\left(w_{2}, h_{3}\right)$ ". The Humean may here appeal to the fact that $h_{1}$ may support $h_{z}$ to a very high degree indeed; certainly, he will say, we 
may suppose that $S\left(h_{1}, h_{2}\right)>S\left(w_{2}, h_{3}\right) \cdot{ }^{3}$ It still remains the case that the Humean's two premises do not entail his conclusion.

The major error in the argum $n$ nt is due to the Humean's being unduly impressed by the belief that in some sense the available bodies of evidence are conflicting. What is important is which hypothesis is best confirmed by our total body of evidence. Even though $w_{1}$ supports $h_{1}$ and $h_{1}$ supports $h_{2}$ to a very high degree indeed, it may well still be the case that $S\left(w_{1}, w_{2}, h_{1} . h_{3}\right)>S\left(w_{1}, w_{2}, h_{1} \cdot h_{2}\right)$, in which case it will be rational to believe that $h_{3}$ is truc. The argument is based upon a neglect of the inductive fallibilism which Hume himself taught us.

A restatement of a Humean position: The historian is faced with a complex body of documents, eye-vitness accounts, ctc., which he must sift to determine what actually happened. In evaluating the available testimony the historian must use his background knowledge of what is probable or improbable, possible or impossible. This will be based on both his knowledge of what has actually happened in similar circumstances in the past, and also indirect theoretical grounds for supposing that so-and-so will or would occur in such circumstances. If this background knowledge makes it more probable that the cvent did not occur than the testimony makes it probable that the event did occur, then we will be justified in rejecting the hypothesis that the event occurred. In cases where the alleged event is somehow extraordinary and marvellous, we may normally expect the weight of the opposing observational and theoretical evidence to be overwhelming.

This reasoning is fallacious. In terms of our earlicr example, the Humcan is considering whether $h_{2}$ or $h_{3}$ is better supported by the evidence. The evidence in favour of $h_{3}$ is $w_{2}$; the cvidence in favour of $h_{2}$ is $h_{1}$, together with certain theoretical statements $t$. The claim is that an adequate reason for our accepting $h_{2}$ instead of $h_{3}$ is that $\mathrm{S}\left(\mathrm{h}_{1}, \mathrm{t}, \mathrm{h}_{2}\right)>\mathrm{S}\left(\mathrm{w}_{2}, \mathrm{~h}_{3}\right) .{ }^{4}$ But this last sentence is false. The question of which hypothesis is better supported by the evidence is the question of which hypothesis is better supported by our total evidence, namely $\left(h_{1}, t . w_{2}\right)$. And even if the degree to which $S\left(h_{1}, t, h_{2}\right)>S\left(w_{2}, h_{3}\right)$ is very great indecd, it may still well be the case that $S\left(h_{1} . t . w_{2}, h_{2}\right)<S\left(h_{1}, t . w_{2}, h_{3}\right)$.

${ }^{3}$ Of course Hume is the last person entitled, on his own principles, to invoke this premise; we may treat it as an ad hominem manoeuvre.

$4 t$ plays a quite important role here, for even if the number of objects mentioned in $h$ is very large indeed, it still may well be the case that $S\left(h_{1}, h_{3}\right) \times S\left(w_{2}, h_{3}\right)$. To revert to an earlier example, "the pack contains one ace of spades and 51 queens of hearts" supports "the next card drawn is not the ace of spades" to a high degree. Yet surely you will often be justified in regarding my testimony as supporting "the next card drawn is the ace of spades" to a higher degree. 


\section{SOPHIA}

It is indeed the truth of this last sentence which is responsible for our justified giving up of well-confirmed scientific theories on the basis of experimental reports. When a given theory implies that a certain event will not occur, it may or may not be true that the evidence supporting this theory functions as evidence against the hypothesis that the cvent will occur. ${ }^{5}$ Consider a case in which this is true. It will still often $b \approx$ the case that the evidence in question plus a scientist's testimony will together support the hypothesis that the event occurred more than they support the claim that it did not occur. This is so whether or not at the moment one has available a new theory which economically explains all onc's data. It is apparent once again how extremely misleading the Humean principle, "all probability supposes an opposition of expcriments and observations", can be. One notes that scientists are not found to dismiss their colleagues' claims to certain experimental results by saying, "The hypothesis in question is so well supported by past experience that these reports must be duc to repeated experimental error, fraud, or delusion."

A Humean might reply that such practice is justified only by the repetition of such experimental results. But this is mistaken. In astronomy, certain observations may be accepted as grounds for abandoning a theory even though no repetition of the observation occurs for decades. Repeatability fares little better, for it may not even be empirically possible for men to repeat the observations which are accepted as good reasons for abandoning a theory. For example, suppose that the observations are of a K-type star suddenly collapsing, and this is the only $\mathrm{K}$-type star which ever exists.

It certainly is true that in assessing the available testimony the historian must be guided by his background knowledge of what is probable and improbable. But this is to say little. Hume is widely supposed to have established a conclusion of much greater strength and interest, that containcd in the passage quoted at the biginning of this article. I have argucd that this is not the case.

How does this bear on Hume's views on miracles? The Enquiry, Section X, contains, run together, two different accounts of miracle. Firstly, miracle as a transgression of a law of nature by a particular volition of the Deity, or by the interposition of some invisible agent. ${ }^{6}$ Antony Flew has recently expounded the importance of this definition. He points out that according to it miracles are physically impossible. ${ }^{7}$ But what is explicit in Flew exists, at most, only in undeveloped form

5 For "c supports $h$ and he entails c" does not entail "e supports c". 6 Hume, op. cit, p. 115 n.

${ }^{7}$ A. G. N. Flew, Hume's Philosophy of Belief (1961), pp186f; also God and Philosophy (1966), pp.148f. I believe that Flew's views are incorrect; but this should be the argument of another paper. 


\section{HUME ON TESTIMONY TO THE MIRACULOUS}

in Hume and is not in fact central to his reasoning. Rather, Hume's own argument depends upon a characterisation of miracle as the limit case of the extraordinary and marvellous, viz., an event of such a kind that there is uniform experience "against" its occurrence. For textual evidence, consider Hume's admission that "there may possibly be miracles, or violations of the usual course of naturc, of such a kind as to admit of proof from human testimony", c.g., total darkness covering the earth for eight days in January 1600.8 Here "miracle" and "violation" cannot be understood as on the first account. (One must content oneself with the negative point, since it is also unclear how the specific case falls under the second account. For Hume persuades himself that such an event might admit of proof only by describing it in such a way - viz., "example of corruption in nature, etc." that there is not a uniform experience against events of that kind.) ${ }^{9}$ Consider also Hume's discussion of testimony to a dead man's being restored to life: "I weigh the one miracle against the other . . . and always reject the greater miracle". ${ }^{10}$ This is intelligible on the second, but not on the first account.

Thus Humc's rcasoning concerning our knowledge of miracles may be set out as follows:

(1) [Paragraph quoted at the beginning of this article.]

(2) There is a uniform experience against every miraculous event.

(3) Therefore there is a direct and full proof against the existence of any miracle; nor can such a proof be destroyed, or the miracle rendered credible, but by an opposite proof, which is superior; and even in such a casc, our degree of assurance should correspond only to the difference in degrees of strength of the two proofs.

(4) Testimony for miracles associated with the popular religions is of a kind which has often been found to be unreliable.

(5) Thereforc a miracle can never be proved so as to be the foundation of a systcm of religion.

The validity of this argument is open to serious objections, but these have not been the concern of this paper. I have argued that (1) is false, and have warned of the dangers of the word "against" in (2). I conclude that Hume's argument for (3), and so for (5), is unsound.

sHume, op. cit., p127.

${ }^{9}$ Clearly almost any event can trivially be so redescribed. This underlines the fact that the hypotheses to be evaluated are of the form "there occurred an event of type $F$ ", where " $F$ " is some particular predicate.

10 Hume, op. cit., p116. 